\title{
Worlds, Capabilities and Well-Being ${ }^{1}$
}

A large dairy animal approached Zaphod Beeblebrox's table...

"Good evening," it lowed and sat back heavily on its haunches, "I am the main Dish of the Day. May I interest you in parts of my body?...

"That's absolutely horrible," exclaimed Arthur..."I just don't want to eat an animal that's standing here inviting me to,...

"Better than eating an animal that doesn't want to be eaten," said Zaphod.

\section{Life-Adjustment and Life-Improvement}

Advocates of the Capability Approach hold that the capability, or effective freedom, to attain valued functionings as well as their actual attainment contributes to well-being. Granting that capabilities as well as attainments are of value, we recognize neverthTheeless that not all capabilities contribute to well-being: as Sen himself notes, the capability of achieving bad, awful and gruesome outcomes does not make us better off.

Sen leaves open the question of how we are to distinguish those capabilities that benefit us from those which do not. He suggests however that the cut should not be made on the basis of whether or not states produce utility or the extent to which they produce utility (Sen 1993). ${ }^{2}$ Following Sen, Martha Nussbaum argues further that no subjective account of well-being is adequate to the task. Reflecting on the lives of poor women in developing countries she suggests that their preferences have been "deformed" by poverty and oppression and argues that preferentism, because it is a subjective theory, cannot provide an adequate rationale for promoting social justice (Nussbaum 2000). "Embraced as a normative position," she writes, "subjective welfarism makes it impossible to conduct a radical critique of unjust institutions (Nussbaum 2000)." It cannot explain why governments, NGOs or socially concerned individuals should attempt to improve the condition of the poor and oppressed who are reconciled to their fate and satisfied with the circumstances of their lives.

\footnotetext{
${ }^{1}$ The original publication is available at www.springerlink.com

${ }^{2}$ Sen's own understanding of well-being differs from traditional preferentist accounts in two respects. First, on Sen's account, a variety of human acts and states are important in themselves - not just because they may produce utility, nor just to the extent that they yield utility. Secondly, Sen holds that the "capability," the effective freedom to achieve valued states of being and doing, as well as the actual attainment of valued states, contributes to wellbeing.
} 
Critics therefore suggest that without some "objective" account of well-being we cannot explain why satisfying some preferences is, as we believe, better than satisfying others, why satisfying some preferences may leave us on net worse off or why, in a range of cases, we should reject lifeadjustment in favor of life-improvement.

My aim is to defend a subjective welfarist account of well-being against such objections by reconstructing the Capability Approach as a preferentist account of well-being. According to the proposed account, Broad Preferentism, preference satisfaction alone-possible as well as actual-is of value. States of affairs contribute to well-being because and to the extent that they satisfy actual or nearby possible preferences and are fruitful, that is, compatible with a range states that satisfy further actual or nearby possible preferences. It is the capability of attaining such valued states that makes us better of.

Broad Preferentism solves the problem of adaptive preference. Individuals whose preferences are "deformed" are satisfied with fruitless states of affairs, which constrain their options so that they are incapable of satisfying a wide range of nearby possible preferences - preferences they "could easily have had." Recognizing the value of capabilities as well as actual attainments allows us to explain why individuals who satisfy "deformed" or perverse preferences may not on net benefit from doing so. More fundamentally, it explains why some states are, as Sen notes, bad, awful or gruesome while others are good, excellent or superb without appeal to any objective account of value.

Sen's fundamental insight is that the effective freedom to attain valued states makes us better off even if we choose not to exercise it. While this insight is by no means idiosyncratic, it is controversial. How, skeptics wonder, can capability as such - the mere possibility of attaining valued states - make us better off?

The goal of the current project however is not to respond to this worry. It is rather to show that if we hold that merely possible states of affairs can actually benefit or harm us, then we can deploy the machinery of possible worlds to develop a unified account for a range of outstanding problems concerning well-being and rational choice, including but not limited to the adaptive preference problem. I argue that if Sen is correct, then his insight that mere possibilities are of value can be exploited to do more work without recourse to an objective list theory like Nussbaum's.

Arguably, ceteris paribus, we should prefer an account of well-being that is monistic and subjectivist to an irreducibly pluralistic objective list theory like Nussbaum's. Unified theories are to be preferred to piecemeal explanations and objective accounts of well-being that purport to ground the requisites for the good life in the structure of Being or essential human nature seem suspiciously obscurantist. Broad preferentism is a friendly amendment to Sen's Capability Approach that renders it both monistic and subjectivist. 


\section{Broad Preferentism}

Broad Preferentism is a subjective account of prudential value insofar as it affirms agent sovereignty - the doctrine that "what is good for each person is entirely determined by that very person's evaluative perspective (Arneson 1999)." On the broad preferentist account however an individual's evaluative perspective includes not only her actual preference-ranking but her preferences at other nearby possible worlds. A state of affairs contributes to an individual's well-being if it satisfies her actual preferences or preferences she "could easily have had," that is, those she has at "nearby" possible worlds, where her basic psychology and circumstances are similar to those she has at the actual world. Capabilities as well as achieved functionings are of value because they are instances of possible preference-satisfaction. On the broad preferentist account:

A state of affairs contributes to an individual's well-being if it satisfies her actual preferences or preferences she "could easily have had," that is, those she has at "nearby" possible worlds, where her basic psychology and circumstances are similar to those she has at the actual world.

On this account, the satisfaction of our actual preferences contributes to well-being - a view that all preferentists, whether narrow or broad, accept. It says also that if we prefer $S$ then the option of getting it, even if we choose not to exercise that option, makes us better off and, moreover, that if our desiring $S$ is a nearby possibility then even though we do not actually prefer or choose it, we are better off for having the capability of getting it. In every case what contributes to well-being is preference satisfaction broadly construed as the conjunction of a preference for a state of affairs and that state of affairs' obtaining - though not necessarily at the actual world or even at the same possible world. Broad preferentism is therefore a monistic theory: only (actual or possible) preference-satisfaction makes us better off.

It remains to be seen how much better off. Intuitively, even if we grant that the capability of getting things we do not actually want contributes to our well-being, the capability of getting things we do want contributes more. On the current account, the extent to which a state of affairs, $S$, contributes to an individual's well-being is a function of the "distance" from the actual world to the closest world at which she both prefers and chooses $S$ and $S$ 's fruitfulness, that is the range of valued states with which $S$ is compatible: the closer the world at which an individual chooses $S$ and the wider the range of valued options with which $S$ is compatible, the more the capability of getting $S$ contributes to her wellbeing. ${ }^{3}$ States are of value, therefore, with respect to centered worlds, that is, possible worlds centered

\footnotetext{
${ }^{3}$ Fruitfulness is therefore of instrumental value insofar as the fruitfulness of a state makes it possible for the agent to attain other states which satisfy his actual or nearby possible preferences.
} 
on individuals at times, and a state of affairs contributes to an individual's well-being in a world at a time to the extent that it (i) is relevant, (ii) obtains at a nearby world and (iii) is fruitful. We understand these conditions as follows:

(i) Relevance: A state, $S$, is relevant to an individual's well-being at a world, $w$, to a degree commensurate with the distance from $w$ to the closest world, $w^{\prime}$, at which she prefers $S$. A world, $w^{\prime}$, is close to $w$ to the extent that $w^{\prime}$ is a world in which the psychology and circumstances of the individual on which $w$ is centered are similar to her psychology and circumstances at $w^{\prime}$.

I have no interest in online role-playing games but, given the sort of person I am and my circumstances, I know that I could easily get hooked: there is a nearby possible world at which I prefer online role-playing and so that activity is relevant for me. I have no interest in ballet either but even beyond that, given my tastes and circumstances, there is no way I could get hooked on it: the world at which I prefer ballet is remote and so ballet-going irrelevant to me.

The capability of attaining states that are relevant to me contributes to my well-being and, all other things being equal, contributes to a degree commensurate with the distance of the world at which I prefer the states in question. Since the actual world is closest to itself, the capability of attaining states I actually prefer contributes most to my well-being. However the capability of attaining states that I “could easily" prefer - those I prefer at nearby possible worlds - also contributes.

The availability of a variety of amenities in my area of which I don't take advantage but might easily want to use - beaches, parks and a wide range of restaurants and bars - contributes to my wellbeing. By contrast, the capability of achieving states that I only prefer at remote worlds does not contribute significantly to my well-being. I not only actively dislike any activity in which I have to sit in an audience: I would have to be a very different sort of person to prefer such activities - my aversion to these activities is modally deep. The availability of concert halls, movie theaters and sports stadiums in my area contributes nothing to my well-being since worlds at which I like going to concerts, to the movies or to sports events are remote.

But that's only me. Broad preferentism is a subjective theory. The relevance of the capability for attaining some state, $S$, to an individual's well-being is determined by that individual's evaluative perspective, understood here as his transworld preference structure: lots of people don't mind sitting still and like going to the movies. The availability of concert halls, movie theaters, and sports stadiums makes them better off.

All other things being equal, the more relevant a preference is for us the more the capability of satisfying it contributes to our well-being. Capability however, like relevance, is also a matter of degree: 
(ii) Capability: An individual, $i$, is capable of attaining a state, $S$ at $w$, to a degree commensurate with the distance from $w$ to the closest world, $w^{\prime}$, at which $S$ obtains. The greater the distance between a world, $w$, and the closest world, $w^{\prime}$, at which a state $S$ obtains, the less capable $i$ is of attaining $S$ at $w$. An individual is capable of attaining $S$ at $w$ to degree 1 if $S$ obtains at $w$ and to a lesser degree, between 0 and 1 if it obtains at some "nearby" non-actual possible world-a world in the neighborhood of $w$. If he is not capable of getting $S$ then we may say that he is capable of getting it to degree $-1 .{ }^{4}$

Capability as understood here is a relative modality: amongst those states of affairs that are logically possible, there is a restricted range of states that I am capable of achieving (to some non-zero degree) and a boundary, perhaps fuzzy, between those states which obtain at nearby possible worlds and so represent "real possibilities" for me and those which are no more than logically possible. It is logically possible for me to run a 4-minute mile but that is not something that I am capable of doing. I am capable of running a 10-minute mile; whether or not I am capable of running a 7-minute mile I do not know. On the current account, actual preference-satisfaction is the capability of achieving one's preferred state to the highest degree. The higher the degree of capability I have of attaining a state I

\footnotetext{
${ }^{4}$ Why assign these numbers? Because we want to accommodate two intuitions. First, we conceive of actually $\phi-$ ing as the limiting case of the capability of $\phi$-ing. Capabilities and attainments both benefit us not because they are two different categories of goods which contribute independently to well-being but because attainment is in effect capability to the highest degree. If $\phi$-ing is good for me then having the capability of $\phi$-ing is good for me: that capability is good for me just because $\phi$-ing is good for me, and the extent to which that capability contributes to my well-being depends upon the extent to which actually $\phi$-ing contributes to my well-being. As Sen notes, it is not capability as such that makes us better off but the capability of attaining valued states. Secondly, we note that the incapability of attaining valued states makes us worse off and, arguably, undermines our well-being even if we do not know that we are blocked from attaining such states or feel frustration.

Why does capability suddenly drop to -1 after ranging continuously from 1 down to 0 (and more precisely I'd say that the interval was closed at the high end but open at the bottom so that 0 isn't in it)? Because we want to mark the distinction between states of affairs that are feasible and those that aren't, where wanting what is not feasible makes me worse off. There are certainly degrees of unfeasibleness. It's not feasible for me to be elected to high political office though the world at which I am elected is closer to the actual the world than the world at which I sprout wings and fly so one might say that it's less feasible for me to fly than it is for me to be elected to high political office. It's even less feasible for me to discover the highest prime number because there is no possible world at which I or anyone else does that. But when it comes to well-being, intuitively, the degree of unfeasibleness doen't make any difference. Ceteris paribus, I'm no worse off (or better off) missing by a mile than I am missing by an inch, though I take the point that missing by an inch may make me feel worse. I'm no worse off as a wannabe mathematician on a futile quest for the greatest prime than I am as a wannabe politician aspiring to high political office.

There is however motivation for assigning continuous values from 1 down to 0 for degrees of capability since, intuitively, ceteris paribus states of affairs that are feasible contribute to my well-being to the degree that they're feasible so this is a matter of intuition fitting. Capability, on the current account, is what matters for well-being; outside of the neighborhood of possible worlds which represents states that are feasible all is darkness, where cats are equally gray.
} 
prefer the more it contributes to my well-being so actually satisfying my preference for $S$ contributes more than the mere capability of satisfying my preference..$^{5}$

As Sen suggests I may prefer a state and be capable of attaining it but forgo satisfying my preference out of "commitment" - preference is not tantamount to choice. However, the capability of attaining a preferred state, even if I choose not to exercise it, contributes to my wellbeing. Fasting, Sen notes, is quite a different thing from starving. On the current account, given that I prefer to eat, fasting is better for me than starving because when I fast I have the capability of eating. Eating, however, is better than fasting: when we act out of commitment we typically sacrifice some degree of well-being (Hausman 2005). ${ }^{6}$

All other things being equal, the extent to which a state, $\mathrm{S}$, contributes to an individual's wellbeing at a world, $w$, is a function of the relevance of $\mathrm{S}$ to his well-being and the degree to which he is capable of attaining $\mathrm{S}$ at the closest world, w', at which he prefers it. Consider the following cases where w0 is the actual world centered on an individual, $i$, "P" marks a world at which i prefers $\mathrm{S}$ and “•” marks a world at which S obtains. Let us assume, arbitrarily, that my capability extends only to worlds that are no more than four worlds away so that if I prefer a state, S, at w and the world closest to $\mathrm{w}$ at which $\mathrm{S}$ obtains is more than four worlds away, I am not capable of satisfying my preference for $\mathrm{S}$. Let $\mathrm{w}_{0}$ be the actual world, let $\mathrm{w}_{1} \ldots \mathrm{w}_{10}$ represent worlds in order of increasing distance from $\mathrm{w}_{0}$ and consider the following cases:

\footnotetext{
${ }^{5}$ How much does mere capability matter? The extent to which a preferred state of affairs contributes to an individual's well-being at a world, $w$, is a function of distance between $w$ and the world at which he prefers that state and it obtains. Intuitions about the shape of this function vary widely. Some people think that even states that satisfy preferences at very close possible worlds don't matter very much so that the graph of the well-being function drops off precipitously once we move beyond the actual world. Other people are modally risk-averse: we feel that the mere possibility of satisfying preferences we might have had, however remote those possibilities, is really important. Broad preferentism only says that the possible satisfaction of some merely possible preferences sometimes contributes to well-being: we leave open the question of what shape the function takes.

${ }^{6}$ Daniel Hausman discusses different notions of "preference" that figure in economics and the literature on rational choice. On the strict revealed preference account, preference cashes out as choice so I cannot choose something I do not prefer: commitment is impossible. It is widely recognized however that, as Hausman has argued, revealed preference is a non-starter for any plausible preferentist account of well-being. I am assuming for the purposes of this discussion a folk-psychological account of preference, which does not identify preference with choice and is compatible with commitment. "Of course I would rather be eating that steak but I'm fasting in solidarity with the starving masses and sending my money to Oxfam." The folk say that what I would rather do is what I would prefer to do and that, in this case, I am not doing what I prefer to do: I am acting out of commitment.
} 


\section{Ways Worlds Could Be}
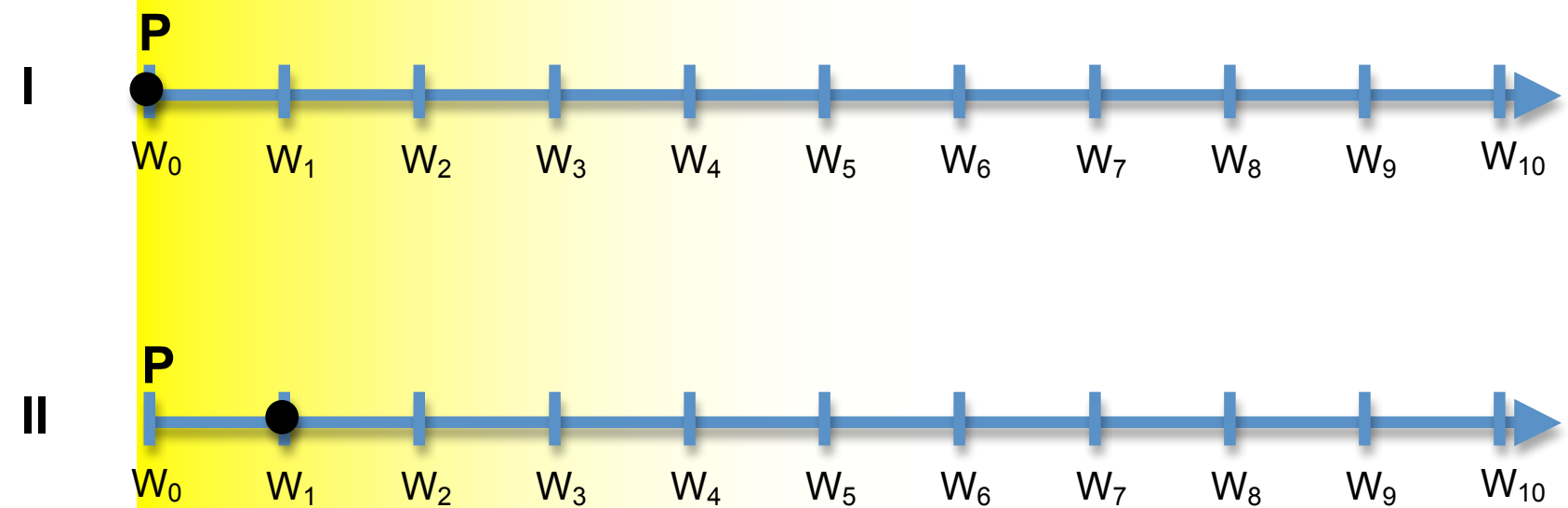

III

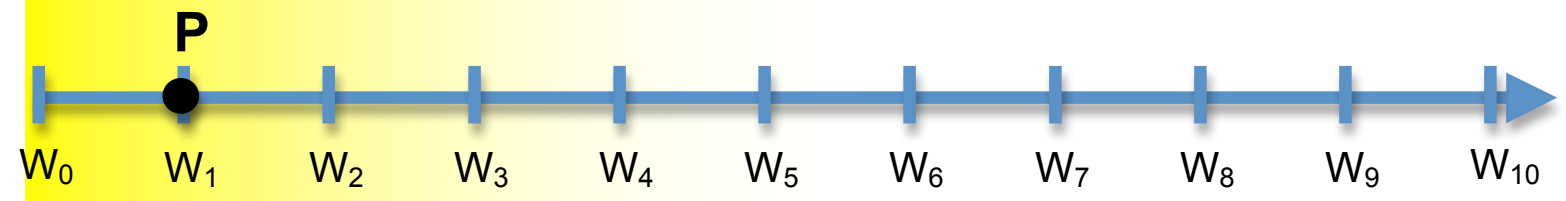

IV
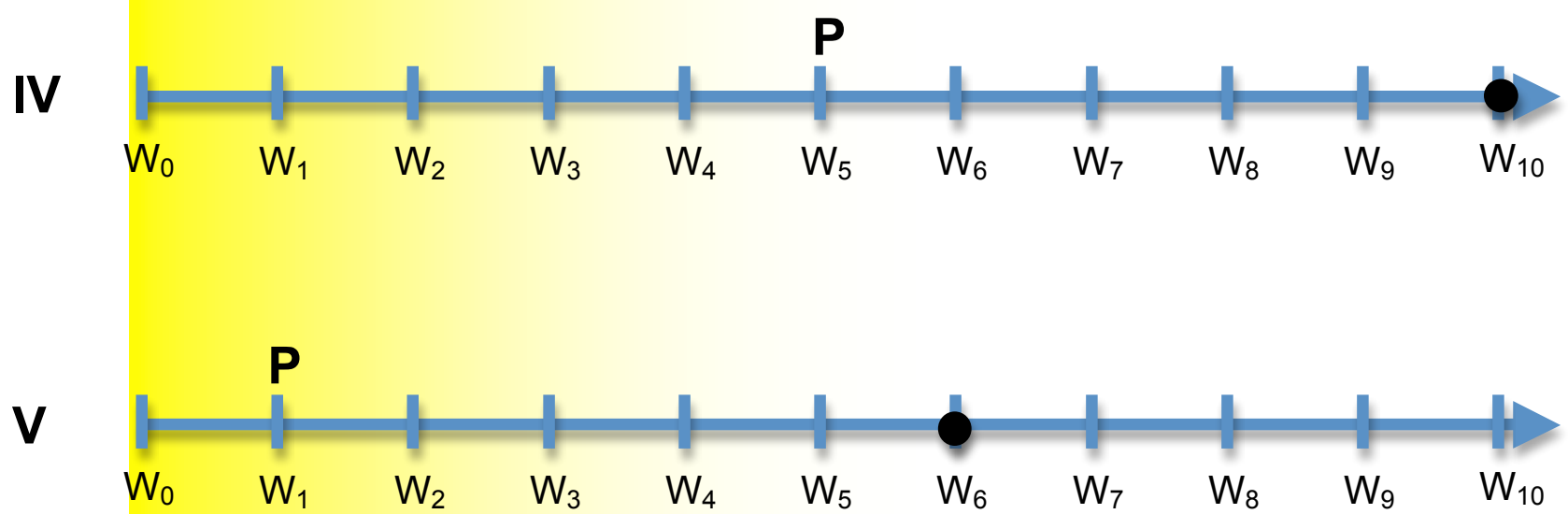

VI




In Case I, I actually prefer $S$ and satisfy my preference: this is as good as it gets. In Case II, I prefer $S$ and am capable of getting it, but forgo $S$ out of commitment. I am, therefore, less well off since my preference for $S$ at $w_{0}$ is only satisfied, say, to degree 0.9 rather than to degree 1 . How much less well off? We could stipulate that the amount of well-being a state, $S$, contributes to an individual, $i$, at a world, $w$, is the product of $S$ 's relevance for $i$ at $w$, the degree to which $i$ is capable of attaining $S$ at $w$ and $S$ 's fruitfulness for $i$. It does not matter for our purposes here how we do the math so long as we recognize that the value of mere capabilities may be greater than zero, that an individual's capability of achieving a state, $S$, is only of value if he prefers $S$ at some nearby world, that the closer the world at which he both prefers and gets $S$ the better off he is and that the incapability of satisfying relevant preferences leaves him worse off.

In case III, the world at which I both prefer and attain $S$ is nearby: I don't actually prefer $S$ but could easily have preferred, and gotten, $S$. Since I prefer $S$ at a nearby possible world, $S$ is relevant to my well-being at $w_{0}$ and I am better off because I have the capability of getting it: there is a world at which I attain S, viz. $w_{1}$, in the neighborhood of $w_{0}$.

Case IV is more complex. At $w_{5}$ I prefer $S$ but am not capable of getting it since the closest world to $w_{5}$ at which $S$ obtains, $w_{10}$, is worlds away. At $w_{5}$, the capability of satisfying my preference is negative so I am badly off at $w_{5}$. However I am not badly off at the actual world, $w_{0}$ because my merely possible preference for $S$ is irrelevant: $w_{5}$, the world at which I prefer $S$ is remote from the actual world.

As things actually are with me, there is a remote possible world, $w_{5}$, at which I want to be like Paris Hilton. The world at which I am like Paris Hilton - stinking rich and famous for being famous is even more remote from the actual world and not even in the neighborhood of $w_{5}$. So, at $w_{5} \mathrm{I}$ am frustrated and badly off. However that frustrated preference itself is so remote from the way things are with me at $w_{0}$, that its being frustrated makes no difference to me: my frustration at $w_{5}$ does not detract from my well-being at $w_{0}$.

In Case $\mathrm{V}$ by contrast my frustrated possible preference for $S$ is relevant to my well-being at the actual world because $w_{l}$ is nearby.

I am watching a riveting movie and have no desire to get up and go somewhere else or do anything else. Good thing I don't because I can't: I'm on a transatlantic flight. Still, I'm pretty badly off because I'm an antsy person for whom the desire to get up, walk around and do something else is always lurking at a very close possible world regardless of how much I like what I'm doing or how absorbed I am in a project. I like the movie and enjoy the ministrations of attentive flight attendants who periodically bring meals, drinks and nibbles and deliver hot towels with tongs, but I am not as 
well off as I would be watching that riveting movie at home where even though I wouldn't get up, walk around or do anything else, I could.

Case VI is the worst-case scenario. I actually want $S$ so that state is relevant to my well-being to the highest degree, but my capability of getting it is negative: given my inability to get $S$ my preference for it makes me worse off.

The extent to which a given state contributes to my well-being thus depends on the distance of worlds at which I prefer it and get it. Hedonists will resist the suggestion that merely possible states of affairs benefit us because the goings-on at other possible worlds, even close ones, do not enter into experience. But hedonists are a lost cause. I suggest that if we are preferentists and so recognize that states of affairs that do not enter into experience may benefit or harm us, we should recognize that merely possible states of affairs make a difference - that is to say, if we are going to be preferentists, we may as well be broad preferentists.

Nevertheless, granting that merely possible states of affairs may contribute to well-being, and that a given state of affairs is relevant to a degree commensurate with the distance of the world at which it obtains, we also want to know how different states contribute to well-being. Intuitively, all other things being equal, different states may contribute different amounts of well-being so that where individuals prefer different states, even when they get what they most want they may not be equally well off.

I prefer being an academic and living the middle class life that attaches to that, with a house in a leafy suburb, a car, a Mac laptop and a chocolate lab; Jayamma, one of Nussbaum's subjects, whose wants are modest, is content with a basic cinderblock dwelling the size of my living room, without a car, computer or dog. Some people's preferences are not merely modest but positively perverse: there were ascetics in Late Antiquity who spent their lives on pillars or in hollow tree trunks and, more recently, there have been a spate of highly publicized cases of individuals clamoring to have healthy limbs amputated. Intuitively, even at the top of our respective preference rankings, even if we all get just what we want, I am better off than Jayamma and certainly better off than the ascetics or amputees.

Moreover I see no compelling reason to believe that Jayamma is either uninformed or unreflective so that her manifest preferences fail to reflect her true or idealized preferences. I've watched Lifestyles of the Rich and Famous on TV and even visited some very fancy houses myself. I am well-informed but upon reflection and due deliberation do not think that I would prefer a bigger house, more stuff or a more lavish lifestyle. I am at the top of my idealized preference ranking and so, I suggest, is Jayamma. The rich and famous whose lifestyles I've observed might doubt that this is my true or ideal preference: surely if I were sufficiently informed and had really reflected I would not be 
satisfied with my house or lifestyle. They certainly would not be satisfied without a swimming pool, sauna or room for a pony.

But this move is ad hoc: by their lights nothing will count as adequate information or satisfactory reflection unless it yields what they regard as the correct preferences. Granting that the preferences whose satisfaction counts for well-being are informed preferences we should be careful to avoid surreptitiously introducing objective standards of betterness and inferring that if someone does not want what is by those standards better, then their preferences cannot count as sufficiently informed or reflective. We might not be happy with Jayamma's house or with her computerless, dog-free lifestyle but we cannot infer that she is uninformed or unreflective, or that she is not at the top of her actual idealized preference ranking.

Of course preferences change. If I acquired a swimming pool, sauna and room for a pony I might quickly come to prefer these goods and wonder how I could ever have done without them. But that is quite a different thing from saying that I really wanted these things all along and would have realized it if I had been sufficiently informed and reflective. By the same token, Jayamma's preferences could change. She might come to want a bigger house and more stuff. But that is not to say that she really wanted these things all along but just didn't realize it because she was not sufficiently informed or reflective. I see no reason to assume that she is not at the top of her preference-ranking even if, by our standards, her preferences are overly-modest, and even though we believe that she is less well-off than we are because her life is circumscribed and constrained.

This is a hard case for narrow preferentism, according to which the only means of making such interpersonal comparisons of well-being is via the "Zero-One Rule" - by setting the welfare value of states at the top and bottom of individuals' preference-rankings to 1 and 0 respectively, and assigning values to intermediate states accordingly (Hausman1995; Weintraub 1996; Hausman 1997; [reference to author paper suppressed for review]). On this account, all individuals at the tops of their actual-world (informed) preference-rankings are equally well off. This however seems manifestly false - and the broad preferentist can explain why without recourse to irreducibly objective criteria for betterness.

Some states are more fruitful than others - they are compatible with a wider range of other states that satisfy individuals' actual or nearby possible preferences. I am better off satisfying my preference for the life of a middle class academic than the ascetic is in satisfying his preference for living in a hollow tree trunk because the life I live is more fruitful.

(iii) Fruitfulness: the fruitfulness of a state, $S$, for an individual, $i$, at a world, $w$, is a function of

(a) the degree of capability $S$ confers, that is, the range of states $S_{1} \ldots S_{n}$ with which $S$ is compatible and 
(b) the extent to which each of the states, $S_{1} \ldots S_{n}$ is relevant to $S$ 's well-being

Broad preferentism is a subjective theory since the extent to which such states are relevant to an individual's well-being depends on her (transworld) evaluative perspective. Nevertheless, the fruitfulness clause introduces an "objective" condition on well-being, (iiia), which accounts for our conviction that ceteris paribus, regardless of anyone's preferences, some states are inherently better than others. The compatibility of an individual's state with other states is "objective" insofar as it does not depend on his preferences or other psychological states. The compatibility of $i$ 's state with a range of other states will not make him better off if he does not prefer these states at the actual world or any nearby possible world, that is if they are not relevant to him, but it cannot make him worse off. The incompatibility of $i$ 's state with a range cannot make him better off but may make him worse off. Some people want healthy limbs amputated: we think that this is a lousy preference to have since satisfying it closes off possibilities. Being an amputee is incompatible with a wide range of states and activities and all other things being equal, states of affairs that diminish our capabilities make us worse off.

On the current account, the states that are best objectively, all other things being equal, are those that enhance our capabilities and so expand the range of possible preference satisfaction. This not only backs our intuition that some states are inherently better than others regardless of what we actually prefer but it defines prudential value in the intuitively correct way. On this account push-pin is as good as poetry since the enjoyment of both of these activities is compatible with the same wide range of states, but ceteris paribus money, power and prestige are of more value than wisdom and virtue. Acquiring wealth, power and prestige expands the range of our capabilities. Acquiring wisdom, as distinct from technical competence and job skills, does not facilitate preference-satisfaction, and virtue may actually impede it: conscience makes cowards of us all.

One of the chief technical difficulties in the current account of well-being is the question of how we are to individuate and count states of affairs. As Sen notes "it is always possible to add trivially to the number of options." Arguably however we do not need to answer this question: intuitively some states expand our capabilities while others restrict them. Nevertheless, as Sen notes, even given a plausible procedure for counting the states we are capable of attaining, it is not merely the number of these states but their character that matters: the capability of achieving bad, awful and gruesome outcomes does not contribute significantly to our well-being. That is why the fruitfulness of a state does not depend only on the range of states with which it is compatible, regardless on what criterion we adopt for individuating and counting states, but on their relevance, as required by (iiib).

I have come into some money - not much, but enough to pay for either breast augmentation or a course in electronics technology at my local community college. Each alternative opens a range of 
career options for me. Breast augmentation opens possibilities for working as a stripper, waitressing at Hooters and sex work; the electronics course opens a very different range of career options. Personally, I prefer a career in electronics and regard stripping, waitressing and whoring as bad, awful and gruesome alternatives, so I'm better off with the electronics course. But that's just me. There is nothing inherently better in being technician (or a philosopher) than in being a stripper: de gustibus. The current account accommodates that intuition.

Broad preferentism is thus a subjective theory. What distinguishes an individual's good, excellent and superb options from her bad, awful and gruesome ones is their relevance for her: alternatives which are compatible with a wide range of other states are prima facie better than those which close off options, but their fruitfulness for an individual depends on the extent to which those options are relevant to her, that is the distance of the world at which she prefers the states with which they are compatible. Consequently, it might be worthwhile for an individual to trade off a state that yields a wide range of options in which she has little interest for one that restricts her options, but provides a few opportunities that she prefers.

I can choose to train as an engineer or go to grad school in philosophy. A degree in engineering would open a wide range of career options to me; with a philosophy degree there is just one career path and I am not likely to have any choice about what job I take or where I live. Given the transworld structure of my preferences however, the wide range of options that would be open to me with an engineering degree are irrelevant: they do not satisfy preferences I have at any nearby possible worlds. The few options I would have with a philosophy degree by contrast are exactly what I want so that is what I choose: philosophy for me is the more fruitful alternative-the pearl of great price for which it is worth trading off a wide range of other options. The range of options with which a state is compatible at a given world is an objective matter of fact but the fruitfulness of an option for an individual depends on that individual's actual and nearby possible preferences and hence on his evaluative perspective.

The account proposed here fits our intuitions about a range of otherwise puzzling cases such as those I have considered. More deeply however it explains why we believe that over and above getting what we actually want, effective freedom as such makes us better off. The current account captures that global intuition but, more importantly, it provides a unified account of why, in addition to getting what we want, the freedom to get things we may not actually want contributes to well-being. Preference-satisfaction is the common coin: the difference between the actual preference-satisfaction and capability is modal. 


\section{Solving the adaptive preference problem: the content of preferences}

Since preference-satisfaction is what matters for well-being, albeit the way in which it matters is complex, individuals are always worse off for being unable to achieve states they prefer. However we can make people who cannot get what they want better off in two different ways: by adjusting their preferences or by improving their capabilities. Graphically, considering Case VI, this is the difference between sliding $\mathbf{P}$ to the right so that it is irrelevant and sliding $\bullet$ to the left so that the $\mathrm{P}$ is satisfied.

Critics worry, with cause, that narrow preferentism cannot explain why one procedure is better than the other, and argue that preference utilitarianism as ordinarily understood gives the wrong answer. A traditional preference utilitarian looks for the cheapest way to secure desire satisfaction: if getting people to prefer what is on offer by brainwashing or doping is as effective as improving the circumstances of their lives but cheaper then that is what we should do. For the same reason, if disadvantaged individuals are satisfied with impoverished, oppressive conditions then we should certainly not pay the substantial costs involved in raising their consciousness and changing their life circumstances. This is Nussbaum's beef with "subjective welfarism”: she notes, correctly, that victims of "adaptive preference" are badly off even though they have successfully "adjusted" to deprivation and oppression.

Broad preferentism however can explain why life-improvement is better than life-adjustment in the cases where we, intuitively, believe that it is: it solves the problem of adaptive preference. Expensive tastes are easily acquired: even if disadvantaged individuals are indifferent between their meager and constrained circumstances and what we should regard as more desirable conditions, the preference for a better life is lurking at nearby possible worlds. ${ }^{7}$

Consider Jayamma who works at the local kiln hauling bricks for a pittance, which her husband appropriates and spends as he pleases. As things actually stand, at $w_{0}$, she is satisfied with the arrangement - indifferent between it and other states of affairs. It would cost nothing to let Jayamma be and that is what traditional preference utilitarians will recommend: if she is at the top of her preference ranking then she is doing as well as privileged individuals who want more and get more, and better than affluent individuals who, because they have very expensive tastes are not satisfied with much, much more. If maximizing overall actual desire-satisfaction is what we're after we should use

\footnotetext{
${ }^{7} \mathrm{I}$ 'm assuming that in the real life circumstances Nussbaum describes, victims of adaptive preference do not actually prefer deprivation to more favorable circumstances because this is what the stories she tells suggests. The women she describes whose preferences she claims have been "deformed" are at most indifferent between the conditions of their lives and what we should regard as improvements: they do not think that it is worthwhile trying for improved conditions. Nussbaum's stories however do not provide any reason to think that they strictly prefer the conditions of their lives or that, given the opportunity, they would reject higher wages, better working conditions, better sanitation and health care or more control over their money.
} 
the money we might have spent raising Jayamma's consciousness and improving her life circumstances to accommodate the expensive tastes of greedy individuals who are dissatisfied at much higher levels of consumption. Moreover if we are interested in equality of well-being, understood as actual preference satisfaction, we get the same result: to make greedy malcontents as well off as Jayamma is with her cinderblock house and job at the kiln, we should have to provide them with much, much more.

This seems wrong. Intuitively, we can get a bigger bang for the buck by investing in Jayamma than by providing luxury items for affluent malcontents. Broad preferentism explains why. Even though Jayamma is satisfied with her situation at $w_{0}$, she could easily prefer a better job at higher pay and control of the money she earns. That state of affairs is, however, out of reach, at $w_{5}$ and broad preferentists recognize that even if Jayamma is at the top of her preference-ranking she is not as well off as more demanding individuals at the top of their preference-rankings.

Jayamma's actual state is distinctly unfruitful because she lacks the capability of satisfying a wide range of other nearby possible preferences. On the current account, because Jayamma's preference for a better job, higher pay and control over her earnings is nearby, at $w_{1}$, and so relevant to her well-being, she is badly off — though not as badly off as she would be if she actually preferred this state of affairs. She would be better off if she had the capability of achieving this state. Moreover this state is fruitful: having better job and control over her earnings would open up a wide range of possibilities for further preference-satisfaction. That is why we should invest in Jayamma.

Of course, it is a matter of empirical conjecture whether the preference for better working conditions, higher pay and control over her earnings is a nearby preference for Jayamma or other poor women. It could be that they are so beaten down that their desire for a better life is remote.

Nussbaum's stories about the response of poor women in developing countries to improved prospects however suggest otherwise. When the poor Indian women whose stories she tells see the benefits of joining women's co-ops and taking advantage of microcredit schemes they jump at the chance to participate - no elaborate therapeutic intervention or extensive personality remodeling is required. Their preferences for improved conditions are nearby and that is why we think it is worthwhile to improve the conditions of their lives. Mutatis mutandis, when the preference for "improved" conditions is not nearby, when it would take aggressive therapy, propaganda and extensive character remodeling to elicit or manufacture them, we question the value of life-improvement programs: we are skeptical about projects intended to reform preferences by advertisers, missionaries and political ideologues. 
The poor women whose stories Nussbaum tells are badly off because their preference for clean water, adequate nutrition, and basic social services are nearby while the means for satisfying these nearby possible preferences are out of reach (Nussbaum 2000). ${ }^{8}$

\section{Where preferences come from}

On the current account, the content of preferences matters for well-being only to the extent that the states one prefers are more or less fruitful, that is, only insofar as achieving these preferred states restricts or expands the scope of further preference satisfaction.

Critics of preferentist accounts of well-being nevertheless suggest that quite apart from questions about the content of preferences, the origin of preference matters, so that where the source of a person's preferences is tainted their satisfaction may not contribute to her well-being. The story is familiar. The advertising industry, a tool of capitalism, manufactures the taste for glitzy gadgets and designer jeans; patriarchy promotes women's quest for extreme thinness; neocolonialism induces people around the world to prefer Western junk food to their native cuisines. Satisfying such tainted preferences, they suggest, does not contribute to well-being.

Still, most preferences that are, allegedly, tainted by their origins are also questionable for other reasons. Glitzy gadgets end up gathering dust: people buy them on impulse, without becoming fully informed or engaging in the cool deliberation that preferentists recommend. Designer jeans are status symbols and, as utilitarians note, a widespread taste for such positional goods undermines overall utility and in the end leaves us all individually worse off. And life in fictional dystopias, where individuals are brainwashed, doped or bred to tow the party line is severely constrained.

In general, when we worry about the tainted origin of preferences it is usually possible to find something else wrong with them, which arguably accounts for the intuition that their satisfaction does not contribute to well-being. Mutatis mutandis, where preferences seem good to us we do not worry about their origins. We applaud anti-smoking campaigns and other public service propaganda, and actively support attempts to instill "values" into our children. In any case, discovering the origins of

\footnotetext{
${ }^{8}$ Nussbaum writes: "I talked to women who were severely malnourished, and whose village had no reliable clean water supply. Before the arrival of a government consciousness-raising program, these women apparently ahd no feeling of anger or protest about their physical situation... Now their level of discontent has gone way up: they protest to the local government, asking for clean water, for electricity, for a health visitor. They protect their food supplies from flies, they wash their bodies more often. Asked what was the biggest change that the government program had brought to their lives, they immediately said, as if in chorus, "We are cleaner now."

Nussbaum's take is that only the "normative approach" she recommends could have achieved this result and, in particular, that "utilitarian preference-based approaches" were inadequate to the task: the women, after all, didn't actually mind filth, squalor and malnutrition so why try to induce more expensive taste - and then spend even more to satisfy them? Broad preferentism explains why.
} 
our preferences does not lead most of us to repudiate them or even feel that we ought to. Moralistic fulminations about the tainted origins of the preference for slimness, or for Western consumer products does not make women, or adolescents in developing countries change their ways.

Arguably life-adjustment programs are suspect just because in the fictions and thought experiments where they figure, and in many comparable factual cases, the preferences they induce are suspect on independent grounds. All other things being equal changing one's preferences to suit environmental conditions is no worse than modifying one's environment to satisfy prior preferences, as suggested by thought experiments that scrupulously avoid introducing features which make induced preferences look bad on independent grounds.

Suppose I am going to spend some time in a place where the requisites for a normal American diet are expensive and hard to come by. I can pack a supply of frozen hamburgers, potato chips and coke to see me through or I can work to acquire a taste for native food. If the costs are the same, intuitively, there is no reason to prefer the former strategy. Our intuition in this kind of case would not, I think, change if, instead of engaging in a program of gustatory self-cultivation, I take a pill or submit to neurosurgery to change my tastes in food, providing the costs and risks of taking the pill or having the operation are the same as the costs and risks of hauling a supply of junk food with me.

Moreover, our intuitions hold firm even where changing tastes to suit environmental conditions comes about through social engineering or propagandizing others rather than selfcultivation. Suppose the climate is changing so that in the future, without deploying expensive agricultural technology, it will not be possible grow the kinds of foods that will allow our children to enjoy the diet to which we are accustomed. In the interests of preference satisfaction we can either invest in the technology or train our children to prefer rice to potatoes and garbanzo beans to peas. Again, if the costs and risks are the same, there seems to be no reason why we should invest in technology to satisfy current tastes rather than changing tastes to suit a changing environment. Indeed, given the costs of technology and the impact of our patterns of consumption on the environment it seems that we most certainly should work on changing our preferences and the preferences of others.

Finally, where changing individuals' tastes provides more options for desire satisfaction, we actively applaud the project. People intentionally cultivate tastes for fine wine and high art. Expensive tastes may impose a burden on society, but most of us believe that self-cultivation promotes individual well-being, providing we have the means to satisfy our expensive tastes and don't lose our appreciation for simpler pleasures in the process. We not only engage in self-cultivation: we train our children to appreciate the finer things and clamor for educational programs, public broadcasting projects and community services to elevate the tastes of the general public. 
On the current account greed is good: the more we want and can get the better off we are. Under conditions of scarcity - the condition of the human race for most of its history - we are better off scaling back our desires, but if we are in a position to choose between extravagant desires together with a wide ranger of options for satisfying them and modest desires together with fewer options we should choose the former. Deltas and Epsilons in Huxley's dystopian Brave New World have few options and only the modest actual and nearby possible preferences tailored to the conditions of their lives. Given the circumstances of their lives, they're better off for not wanting much. But the circumstances of their lives, like their preferences, are precisely not "given": both are intentionally contrived and that is why we regard their condition as deplorable. Things could have been much better for them.

All other things being equal adapting our preferences, and those of others, to suit life circumstances is no worse than adapting our environment to suit preferences: ceteris paribus, wanting what you get is as good as getting what you want. The problem is that all things are rarely equal.

\section{The Restaurant at the End of the Universe}

Some preferences are perverse: they are preferences for states of affairs that would be, for most of us, utterly fruitless. A number of otherwise reasonable people are avid to have healthy limbs amputated, a preference which is not only remote from most of us but which, if satisfied, would prevent them from achieving a wide range of (what we assume to be) their actual and nearby possible preferences. Is it ever worth having a healthy limb amputated? On the current account it depends on whether that is what an individual wants and on how important the capabilities he would lose are from his evaluative perspective, that is, how close the worlds at which he wants to do the things that only people with both arms and legs intact can do to the actual world. ${ }^{9}$

Are there any circumstances in which an individual is better off dead-a uniquely fruitless option? On the current account, that depends on his preferences - not only on whether he wants to be dead but on the opportunity costs of being dead - whether death blocks the satisfaction of relevant actual or nearby possible preferences.

\footnotetext{
${ }^{9}$ Here is a true story. A friend visited an elderly aunt of hers who was diabetic and had just had her feet amputated because of complications. The aunt had "adjusted" beautifully and wasn't in the least bothered. According to my friend, she had spent most of her adult life watching TV, and was looking forward to going into a retirement home where she could watch TV all day while carers "did for" her. She gave my friend various kitchen items and other stuff she wouldn't be needing at the home and then a bunch of socks saying, with a good-natured chuckle, that she wouldn't be needing them anymore. Worlds at which the aunt wanted to take up running, and even worlds where she preferred taking care of her own needs rather than depending on others to do for her, were remote. Given her evaluative perspective the capabilities she lost with the amputations had contributed little or nothing to her wellbeing.
} 
In the Restaurant at the End of the Universe animals are bred to prefer being eaten. Animals who prefer being eaten are badly off whatever happens: if they are not eaten their actual preferences remain unsatisfied; if they are eaten, their deaths close off the possibility of any further preference satisfaction - though this may not be so bad on the current account if, perhaps as a consequence of their breeding, they have no nearby possible preferences for states of affairs that would be blocked by their deaths. Even so, on the current account, it is better to want more and get more, and always better, from the prudential point of view, to be greedy and rich than to be modest and satisfied with less.

Intuitively, animals who do not want to be eaten and are not eaten are better off than animals who want to be eaten and satisfy that preference and Broad Preferentists can explain why. Not being eaten is compatible with a wide range of capabilities for the satisfaction of additional preferences; being eaten is not compatible with any capabilities. Having further actual or nearby preferences and the capability of satisfying them is better than not having them and not satisfying them which is, in turn, better than preferring to survive but having a range of actual and nearby possible preferences frustrated by slaughter. Not being eaten is better than being eaten, but if you are going to be eaten anyway then you are better off preferring that outcome.

If this is correct than preferentism broadly construed to admit the contribution of merely possible preference satisfaction to well-being, supports our intuitions regarding such cases and solves the problem of adaptive preference. Where there is no reasonable possibility of changing the conditions of our lives to accommodate our preferences, we are better off scaling down our preferences. (If we balk at life-adjustment it is perhaps because we are overly optimistic about the prospects for life-improvement!) Where change is feasible however Broad Preferentism explains why improving the conditions of people's lives is better than enabling them to adjust to deprived conditions. We should be greedy if we can and stoical if we must--but should not, in any case, be satisfied with the satisfaction of modest actual preferences since the capability of satisfying nearby possible preferences contributes to well-being.

Broad preferentism thus sets the agenda for what most of us recognize as the Good Life: the serenity to accept the things we cannot change and courage to change the things we can change, a wide range of options from which to choose and the capability of achieving states of being and doing that satisfy our actual and nearby possible preferences. It is therefore is the correct account of well-being.

\section{References}

Arneson R (1999) Human Flourishing versus Desire Satisfaction. In: Paul EF, Miller FD \& Paul J (eds), Human Flourishing. University of Cambridge Press, New York, pp 113-142. 
Arneson R (2000) Welfare Should Be the Currency of Egalitarian Justice. Can J Philos, 30(4): 513514.

Billot A (2002) The Deep Side of Preference Theory. Theory and Decis, 53(3): 243-270.

Brandt RB (1998) The Rational Criticism of Preferences. In: Fehige C, Wessels U (eds) Preferences. de Gruyter, Berlin \& New York, pp. 63-77.

Broome J (1993) Can a Humean be moderate? In: Frey RG, Morris C (eds), Value, Welfare and Morality. Cambridge University Press, Cambridge, pp. 51-73.

Clark DA (2006) The Capability Approach. In: Clark DA (ed) The Elgar Companion to Development Studies. Edward Elgar, Cheltenham.

Cohen GA (1993) Equality of What? On welfare, goods and capabilities. In: Nussbaum M, Sen A (eds) The Quality of Life. Clarendon Press, Oxford.

Elster J (1982) Sour Grapes: Utilitarianism and the Genesis of Wants. In Sen A, Williams B (eds)

Utilitarianism and Beyond. Cambridge University Press, Cambridge, pp. 219-238.

Emmett R (2006) De Gustbus. J Econ Methodol 13: 97-111.

Gaspar D (2004) Human Well-being: Concepts and Conceptualizations. Discussion Paper No. 2004/06, World Inst for Dev Econ Res.

Grüne-Yanoff T (2006) Why don't you want to be rich? Preference explanations on the basis of causal structure. In: Campbell JK, O'Rourke M (eds) Topics in Contemporary Philosophy: Explanation and Causation. MIT Press, Cambridge, Mass. and London.

Harsanyi JC (1982) Morality and the Theory of Rational Behavior. In: Sen A, Williams B (eds) Utilitarianism and Beyond. Cambridge University Press, Cambridge, pp. 39-62.

Haslett DW (1990) What Is Utility? Econ \& Philoso 6:65-94.

Hausman D (1995) The Impossibility of Interpersonal Utility Comparisons. Mind 104:473-490.

Hausman D (1997) The Impossibility of Interpersonal Utility Comparisons--A Reply. Mind 106:99100.

Kahneman D, Wakker PP, Sarin R (1997) Back to Bentham? Explorations of Experienced Utility. Q J Econ 112:375.

Lewis D (1973) Counterfactuals. Harvard University Press, Cambridge, MA.

List C (2004) The Impossibility of a Pareitian Republican? Some Comments on Pettit and Sen

Ng Y-K (1999) Utility, informed preference, or happiness: following Harsanyi's argument to its logical conclusion. Soc Choice \& Welf 16.

Nunan R. Harsanyi Vs Sen: Does Social Welfare Weigh Subjective Preferences? J Philoso 78:586589.

Nussbaum M (2000) Women and Human Development. Cambridge University Press: Cambridge. 
Nussbaum M. Adaptive Preferences and Women's Options. Econ \& Philoso 17:67-88.

Nussbaum M (1999) Sex and Social Justice. Oxford University Press, Oxford.

Nussbaum M (1992) Human Functioning and Social Justice: In Defense of Aristotelian Essentialism.

Political Theory 20:202-246.

Nussbaum M (2000) Aristotle, Politics, and Human Capabilities: A Response to Antony, Arneson, Charlesworth, and Mulgan. Ethics 111:102-140.

Nussbaum M (2001) Adaptive Preferences and Women's Options (Symposium on Amartya Sen's Philosophy). Econ \& Philoso 17:67-88.

Parfit D (1984) Reasons and Persons. Oxford University Press, Oxford.

Quinn WS (1990) The Puzzle of the Self-Torturer. Philoso Stud 59:79-90.

Rabinowicz W, Osterberg J (1996) Value Based On Preferences: On Two Interpretations of Preference Utilitarianism. Econ \& Philoso 12:1-27.

Robyns I (2006) The Capability Approach in Practice*. J Political Philoso 14:3,351-376.

Robyns I (2000) An Unworkable Idea or a Promising Alternative? Sen's Capability Approach Reexamined. Cent for Econ Stud Discussion paper 00.30.

Sen A, Williams B (eds) (1982) Utilitarianism and Beyond. Cambridge University Press, Cambridge. Sen A (1970a) Collective Choice and Social Welfare. Holden Day, Inc., San Francisco.

Sen A (1977) Rational Fools, Choice Welfare and Measurement. Harvard University Press, Cambridge, MA, 1982, 84-106.

Sen A (1999) Development as Freedom. Random House, Inc., New York.

Sen A (1970b) The Impossibility of a Paretian Liberal, Choice Welfare and Measurement. Harvard University Press, Cambridge, MA, 1982, 285-290.

Sen A (1993) Capability and Well-being. In: Nussbaum M, Sen A (eds) The Quality of Life.

Clarendon Press, Oxford, pp. 30-53.

Sen A, Nussbaum M (eds) (1993) The Quality of Life. Clarendon Press, Oxford.

Sumner LW (1996) Welfare, Happiness and Ethics. Clarendon Press, Oxford.

Vallentyne P (2003) Capabilities vs. Opportunities for Well-being. J Political Philoso

Weintraub R (1996) The Impossibility of Interpersonal Utility Comparisons: A Critical Note. Mind 105:661-665. 
